\title{
Droperidol dropped; consultants not consulted
}

\section{A survey of the practice of rapid tranquillisation by consultant psychiatrists in the west of Scotland}

\section{AIMS AND METHOD}

We conducted a postal questionnaire survey of the practice of rapid tranquillisation among 215 consultant psychiatrists in the West of Scotland, before and after the withdrawal of droperidol by the manufacturer.

\section{RESULTS}

One hundred and eighty questionnaires ( $84 \%$ of those sent) were returned. Droperidol had been used extensively, often combined with lorazepam, for rapid tranquillisation. The main replacement suggested for droperidol was haloperidol. About half of the respondents to our survey chose to comment on the withdrawal of droperidol. More than half of the comments were unfavourable, including lack of an adequate replacement and lack of consultation with the psychiatric profession.

\section{CLINICAL IMPLICATIONS}

The abrupt withdrawal of droperidol, partly for commercial reasons, was regrettable. There was no time for an adequate evaluation of possible replacement medications and a lack of consultation with the profession regarding the impact on clinical care.
Droperidol was removed from clinical use from 31 March 2001 onwards, when supplies to its distribution chain were stopped. Droperidol's manufacturer, Janssen-Cilag Ltd., wrote to health care professionals in January 2001 to inform them that the Droleptan product range was to be withdrawn, because of a risk-benefit analysis that had highlighted the potential effect of droperidol on the cardiac QTc interval. The oral preparation was to be withdrawn to prevent its use in 'chronic conditions'. The reason for withdrawal of the injectable form was 'commercial viability'.

We believed that droperidol was used extensively on psychiatric wards for rapid tranquillisation in emergency situations. The term 'rapid tranquillisation' is defined as 'giving psychotropic medication to control behavioural disturbance' (Ellison et al, 1989). Droperidol was recommended in the protocol given in the Maudsley Prescribing Guidelines for the management of 'Acute disturbed or violent behaviour' (Taylor et al, 2001), and had been standard clinical practice for many years (Pilowski et al, 1992). We were therefore concerned that the withdrawal of an effective treatment option would have serious implications.

The purpose of this study was to ascertain prescribing habits before droperidol's discontinuation, to identify what was proposed in its place and to ask clinicians' opinions on the matter.

\section{Method}

\section{Subject selection}

A questionnaire was sent to all known consultant psychiatrists working within the West Scotland region. An initial list of consultants was obtained from the Deputy Regional Advisor for this area with responsibility for collecting Census information. We further clarified the accuracy of this list by contacting relevant medical secre- taries at each hospital. We also requested details of psychiatric subspeciality from the medical secretaries.

Along with the questionnaire, each consultant received a covering letter explaining the purpose of the survey and a stamped addressed envelope. Each questionnaire and return envelope was marked with a code so that non-responders might be identified and sent a second mailing while maintaining anonymity.

\section{Data collection}

The questionnaire was based on a series of questions with tick boxes, and spaces were provided to add further information. A pilot version of this questionnaire was distributed to several consultants within our hospital and subsequently revised.

We began by asking if a consultant team used rapidtranquillisation and if so, whether droperidol was used for this purpose. If droperidol was not used, we asked what was used instead. Consultants were asked the frequency of prescription of droperidol for rapid tranquillisation. Frequency was defined as once a week or more, less than once a week but more than once a month, and once a month or less. Respondents were asked if droperidol was used alone or in combination. We asked about combinations including droperidol with lorazepam, with diazepam or with another drug, the name of which was asked. We also asked what else might be done instead, to give an opportunity for comment on non-pharmaceutical interventions.

Clarification was sought regarding replacement in the combinations of droperidol with lorazepam, diazepam or with another drug. For each combination, we asked what alternative, if any, would be used in place of the droperidol, and if any combined medication would continue to be used. An example of an answer might be droperidol and lorazepam replaced by haloperidol and lorazepam. Again, an opportunity was given to comment on any other potential intervention. We did not ask 
whether each medication was given orally or by injection, because doing so would have made the questionnaire too complicated and we did not want to compromise the

original papers

response rate. Finally, we asked for further comment on the subject of rapid tranquillisation, the withdrawal of droperidol or on any other pertinent matter.

\section{Results}

A total of 215 consultant psychiatrists were identified. The total number of returned questionnaires from both mailings was 180 , giving a response rate of $84 \%$. Three questionnaires were returned uncompleted and three letters were received from consultants stating that they did not have appropriate experience of rapid tranquillisation that would be needed to complete the questionnaire.

Of the respondents ( $n=180$ ), $55 \%$ were identified by subspeciality as general adult psychiatrists, $12 \%$ as old age psychiatrists, $10 \%$ as child and adolescent psychiatrists, $9 \%$ as learning disability psychiatrists, $8 \%$ as forensic psychiatrists, $7 \%$ as substance abuse subspecialists, $5 \%$ as psychotherapists, $2 \%$ as liaison psychiatrists and $2 \%$ as rehabilitation psychiatrists. In this and subsequent breakdowns by subspeciality, some respondents are classified as belonging to more than one subspeciality, so that totals are greater than $100 \%$.

Of the non-responders group ( $n=35), 43 \%$ were general adult psychiatrists, $20 \%$ old age psychiatrists, $14 \%$ child and adolescent psychiatrists, 14\% forensic psychiatrists, $11 \%$ learning disability psychiatrists, $6 \%$ substance abuse psychiatrists, 3\% comorbidity specialists and 3\% psychotherapists.

\section{Use of rapid tranquillisation and breakdown by subspeciality}

One hundred and twenty-six (70\%) of the 180 respondents stated that they or their teams used rapid tranquillisation. Sixty-one per cent of users of rapid tranquillisation were general adult psychiatrists, $12 \%$ old age psychiatrists, $10 \%$ forensic psychiatrists, 10\% learning disability psychiatrists, $4 \%$ substance abuse psychiatrists, $2 \%$ rehabilitation psychiatrists, $2 \%$ child and adolescent psychiatrists and $1 \%$ psychotherapists.

Fifty-four (30\%) of all 180 respondents stated that they did not use rapid tranquillisation. Thirty-three per cent of the non-users were general adult psychiatrists, $28 \%$ child and adolescent psychiatrists, $13 \%$ substance abuse psychiatrists, $11 \%$ psychotherapists, $11 \%$ old age psychiatrists, $6 \%$ learning disability psychiatrists, $4 \%$ rehabilitation consultants and $4 \%$ forensic psychiatrists.

One hundred and twelve (89\%) of the 126 using rapid tranquillisation stated that they used droperidol, alone or in combination. Thirty-one (28\%) of the 112 using droperidol did so once a week or more, 30 (27\%) less than once a week but more than once a month, and $51(46 \%)$ once a month or less.

In the 14 using rapid tranquillisation without droperidol, alternatives suggested included lorazepam (10 replies), haloperidol (8 replies), risperidone (3 replies) and chlorpromazine (1 reply).

\section{Prescribing habits of the 112 droperidol users and their preferences for replacements}

These are shown in Table 1. A minority used droperidol alone, most preferring to combine it with another drug, usually lorazepam. Haloperidol is the most popular replacement for droperidol. Lorazepam, chlorpromazine, zuclopenthixol acetate and olanzapine are less popular choices. More often than not, those who had prescribed droperidol with a benzodiazepine drug continued to prescribe a benzodiazepine drug with its replacement.

\section{Comments section}

Seventy-eight consultants ( $43 \%$ of those returning the questionnaire) commented on the withdrawal of droperidol. Sixty-three $(81 \%)$ of these were users of droperidol. Forty-seven respondents indicated a negative response and five a positive response to droperidol's withdrawal. Typical negative responses included 'outrage, no acute risk' and 'serious implications'. One forthright positive response was 'good riddance'. A consistent theme was lack of an appropriate replacement for droperidol, with comments that haloperidol and chlorpromazine were less effective than droperidol. Attention was also drawn to haloperidol and chlorpromazine having more side-effects and longer half-lives.

Of those who gave a negative response, 44 were users of droperidol. Given that there were 112 users of droperidol, 39\% of those who used droperidol expressed a negative comment regarding its withdrawal. Seven consultants expressed concern that the injectable form of droperidol was being withdrawn for commercial reasons, with such comments as 'commercial not clinical'. All seven were droperidol users, indicating that $6 \%$ of droperidol users commented specifically on the withdrawal for commercial reasons. Only one respondent to the questionnaire chose to comment on non-pharmacological interventions.

\section{Discussion}

Our results show that rapid tranquillisation is practised widely. Seventy per cent of the 180 consultant psychiatrists returning the questionnaire used rapid tranquillisation. This percentage would have been higher still had we excluded clinicians such as psychotherapists who would not be expected to recommend rapid tranquillisation unless advising junior doctors during second on-call duties. The vast majority of those using rapid tranquillisation used droperidol. Over a quarter of droperidol users did so once a week or more often. Over half used it more often than once a month. Most consultants preferred to use droperidol combined with lorazepam. A minority stated that droperidol would be used alone. 


\begin{tabular}{|c|c|c|}
\hline & Frequency & $n$ keeping lorazepam \\
\hline \multicolumn{3}{|l|}{ Replacements for those using droperidol alone $(n=32)$} \\
\hline Haloperidol & $20(63 \%)$ & \\
\hline Lorazepam & $9(28 \%)$ & \\
\hline Chlorpromazine & $6(19 \%)$ & \\
\hline Zuclopenthixol acetate & $5(16 \%)$ & \\
\hline Diazepam & 1 & \\
\hline Intramuscular olanzapine (when available) & 1 & \\
\hline \multicolumn{3}{|l|}{ Replacements for those using droperidol with lorazepam $(n=87)$} \\
\hline Haloperidol & $60(69 \%)$ & 45 \\
\hline Chlorpromazine & $15(17 \%)$ & 10 \\
\hline Zuclopenthixol acetate & $10(11 \%)$ & 6 \\
\hline Olanzapine & $6(7 \%)$ & 6 \\
\hline \multicolumn{3}{|l|}{ Replacements for those using droperidol with diazepam $(n=3)$} \\
\hline Haloperidol alone & 1 & \\
\hline Haloperidol or chlorpromazine, keeping the diazepam & 1 & \\
\hline Another antipsychotic, keeping the diazepam & 1 & \\
\hline \multicolumn{3}{|l|}{ Replacements for those using droperidol with a non-benzodiazepine drug $(n=2)$} \\
\hline $\begin{array}{l}\text { Droperidol plus a 'novel antipsychotic' to be replaced by haloperidol plus lorazepam in } \\
\text { 'disturbed psychosis' or haloperidol plus diazepam in 'dual diagnosis patients' }\end{array}$ & 1 & \\
\hline $\begin{array}{l}\text { Droperidol plus chlorpromazine, with the droperidol replaced by chlorpromazine } \\
\text { or haloperidol }\end{array}$ & 1 & \\
\hline
\end{tabular}

Summed totals of subgroups exceed 112 and percentages exceed $100 \%$ because some respondents indicated more than one choice

Thus, droperidol had been a mainstay of rapid tranquillisation in the West of Scotland. We can be confident that our results represented clinical practice in that area, given that $84 \%$ of all consultant psychiatrists responded to our survey. While practice might vary in other parts of the United Kingdom, there can be no doubt that the management of many patients throughout the country will have been affected by the withdrawal of droperidol. The most common replacement medication for droperidol is clearly haloperidol. Over $60 \%$ of those using droperidol alone or combined with lorazepam indicated replacement with haloperidol. Three-quarters of this group would continue to prescribe lorazepam, now combined with haloperidol.

Of the 78 consultants who chose to comment on the withdrawal of droperidol, over half expressed disapproval and only five approval. Thirty-nine per cent of those who used droperidol expressed a negative comment regarding its discontinuation. Many of those disapproving thought that droperidol was more effective than haloperidol or chlorpromazine, and less prone to cause side-effects. Seven criticised its withdrawal for commercial reasons.

If a patient experienced serious side-effects on droperidol, there is the advantage of a short half-life (Compendium of Data Sheets and Summaries of Product Characteristics (1999-2000)). A Cochrane review (Cure \& Carpenter, 2002) suggests, albeit on limited evidence, that droperidol is more effective than haloperidol. This is consistent with the opinions of many of the consultants.

A minority of consultants suggested chlorpromazine or zuclopenthixol acetate as replacements for droperidol. Chlorpromazine is long-acting, having psycho-active metabolites, may be painful by injection and is prone to cause postural hypotension, especially in older patients (Parfitt, 1999). It is not recommended for rapid tranquillisation in the Maudsley Guidelines (Taylor et al, 2001). Zuclopenthixol acetate is unsuitable for patients who have never previously received neuroleptic drugs. Its long duration of action may be useful, but could be a drawback if the patient's acute disturbance was likely to resolve quickly.

To our knowledge, the psychiatric profession was not consulted about the withdrawal of droperidol. Given its extensive use, as confirmed by our survey, we believe that prior consultation with the profession would have been helpful. Admittedly, the manufacturers may have been concerned by an association of QTc lengthening with use of droperidol, also seen with thioridazine (Reilly et al, 2000), but they clearly stated that the withdrawal of the injectable form of droperidol was for commercial reasons and not for reasons of safety. So the withdrawal of droperidol injection could have been delayed to allow for more detailed discussion and evaluation of replacement medication. For example, one consultant suggested using intramuscular olanzapine, whenever it became available. A randomised controlled study, published after the withdrawal of droperidol, suggests that intramuscular olanzapine, compared with haloperidol, is suitable for rapid tranquillisation (Wright et al, 2001), but at the time of writing, intramuscular olanzapine is not available in the UK.

The abrupt withdrawal of droperidol was regrettable, and we hope that such a problem can be avoided in the future. While carrying out this study, we encountered many problems with taking patients off thioridazine, 
following recent severe restrictions on its use because of its effect on the QTc interval. Several patients had

original papers distressing relapses, and some needed hospital admission. Mechanisms need to be set up to allow discussion with the medical profession about the potentially serious implications for clinical care, when widely-used medication is withdrawn. Cooperation among different drug companies often would be important to allow a smooth transition to alternative, adequately evaluated, medication.

If the withdrawal of a widely used drug is not immediately warranted on grounds of safety, we suggest that planned randomisation to alternative medication, on a multicentric basis, be considered. Such research would immediately cut the prescribing of suspect medication, reducing any potential risk, but would also allow knowledge to advance. Such studies would have been especially valuable in the case of drugs like droperidol, because the practice of rapid tranquillisation has been based largely on clinical experience rather than adequate scientific evaluation (Pilowski et al, 1992; Curen \& Carpenter, 2002; McAllister-Williams \& Ferrier, 2002).

\section{Acknowledgements}

We thank Dr Simon Groves, consultant psychiatrist, for assistance in identifying the study group, and our colleagues for completing the questionnaires.

\section{References}

Compendium of Data Sheets and Summaries of Product Characteristics (1999-2000)pp.627-628. London: Datapharm Publications Limited.

CURE, S. \& CARPENTER, S. (2002)

Droperidol for acute psychosis (Cochrane Review). Cochrane Database Systematic Reviews, 2, CD002830.

ELLISON, J. M., HUGHES, D. H. \& WHITE, K. A. (1989) An emergency psychiatry update. Hospital and Community Psychiatry, 40, 250-260.

MCALLISTER-WILLIAMS, R. H. \& FERRIER, I. N. (2002) Rapid tranquillisation: time for a reappraisal of options for parenteral therapy. British Journal of Psychiatry, 180, 485-489.

PARFITT, K. (ed.) (1999) Martindale:The Complete Drug Reference (32nd edn). London: Pharmaceutical Press.
PILOWSKI, L. S, RING, H. SHINE, M et al (1992) Rapid tranquillisation: a survey of emergency prescribing in a general psychiatric hospital. British Journal of Psychiatry, 160, 831-835.

REILLY, J. G., AYIS, S. A., FERRIER, I. N., et (2000) QTc-interval abnormalities and psychotropic drug therapy in psychiatric patients. Lancet, $\mathbf{3 5 5}$ 1048-1052.

TAYLOR, D., MCCONNELL, $H$, DUNCAN-MCCONNELL, D., et al (2001) The Maudsley Prescribing Guidelines. London: Martin Dunitz Ltd.

WRIGHT, P., BIRKETT, M., DAVID, S. R. et al (2001) Double-blind, placebocontrolled comparison of intramuscular olanzapine and intramuscular haloperidol in the treatment of acute agitation in schizophrenia. American Journal of Psychiatry, 158, 1149-1151.

\section{Declaration of interest}

None.

Gavin Reid Specialist Registrar in Forensic Psychiatry ～* Mark Hughson Consultant Psychiatrist, Leverndale Hospital, 510 Crookston Road, Glasgow G537TU 